\title{
Turner, Benjamin e Antropologia da Performance: 0 lugar olhado (e ouvido) das coisas ${ }^{1}$
}

John C. Dawsey Um dos momentos mais expressivos para se pensar o surgimento da antropologia

USP da performance ocorre nos anos de 1960 e 1970, quando Richard Schechner, um diretor de teatro virando antropólogo, faz a sua aprendizagem antropológica com Victor Turner, um antropólogo que, na sua relação com Schechner, torna-se aprendiz do teatro. Creio que esse encontro seja particularmente propício para se discutir o tema que se enuncia em subtítulo desta mesa: "abordagens teóricas num campo emergente no Brasil" ${ }^{2}$. Evocando-se a etimologia da palavra teoria, que, assim como a de teatro, nos remete ao "ato de ver" (do grego thea), o empreendimento teórico sugere algo que poderíamos chamar, tal como Roland Barthes (1990:85) chamou o teatro, de um "cálculo do lugar olhado das coisas". Daí, o exercício que aqui se propõe: repensar o lugar olhado das coisas na antropologia da performance. Isso, a partir de uma audição dos ruídos.

À primeira vista, ao passo que se detecta na obra de Turner um percurso que vai do ritual ao teatro, na de Schechner emerge um movimento contrário, do teatro ao ritual. Na configuração de movimentos contrários e complementares irrompe um dos momentos originários da antropologia da performance. A seguir, pretendo me deter no percurso de Turner.

Convido os leitores (ou ouvintes) a se imaginar, tal como me imagino, em meio a uma espécie de rito de passagem. Iniciamos com um rito de separação, saindo de um lugar (supostamente) familiar: os estudos de Turner sobre ritos e dramas sociais. 0 movimento nos leva em direção a um lugar menos conhecido, onde nos deparamos, tal como num rito de transição, com um conjunto de escritos ainda não traduzidos de Turner. Nessa experiência de tomb and $w o m b^{3}$, de natureza exploratória e nãoresolvida - no límen de sua obra-, entra-se em contato com alguns dos textos uterinos da antropologia da performance e da experiência. Um detalhe: a noção de drama social reaparece nesse límen sugerindo a possibilidade do terceiro momento de um rito de passagem, o regresso - num rito de reagregação - ao lugar (estranhamente) 
familiar. Porém, ao invés de fazermos esse regresso talvez seja mais interessante explorar o límen da escritura de Turner. Aproveitando o impulso de um movimento que nos leva às margens, vamos, então, às margens das margens. Ali, alguns dos ruídos suscitados por textos de Victor Turner podem evocar o pensamento de Walter Benjamin.

Uma premissa se apresenta: campos emergentes freqüentemente surgem como manuscritos desbotados. A metáfora de Clifford Geertz é sugestiva. O campo da antropologia da performance pode ser lido como "um manuscrito estranho e desbotado, cheio de elipses, incoerências, emendas suspeitas e comentários tendenciosos" (Geertz 1978:20). Mas, uma das intuições de Turner também pode sugerir uma premissa complementar: os lugares onde um texto se desmancha podem ser os mais fecundos.

\section{PRIMEIRO MOMENTO: DO TEATRO AO RITUAL}

Nesse primeiro momento do nosso rito de passagem saímos de um lugar supostamente familiar. Deixamos o "velho" - na verdade, jovem - Turner. Nesse lugar, que se configura no redemoinho dos anos cinqüenta, encontramos algumas de suas idéias originárias. O percurso de Turner pode sugerir um esquema evolucionista, do ritual ao teatro. Mas, nos anos de formação de Turner também evidencia-se um movimento contrário, do teatro ao ritual. No princípio, o teatro. Victor Turner, filho de Violet Witter - uma das fundadoras do Teatro Nacional Escocês - toma interesse pelo estudo de rituais. Além disso, inspirando-se numa estética da tragédia grega, ele elabora um conceito de drama social. O modelo de ritos de passagem de Arnold Van Gennep, pressupondo três momentos, desdobra-se no conhecido modelo de drama social de Turner em quatro: ruptura, crise e intensificação da crise, ação reparadora e desfecho.

Victor Turner produz um desvio metodológico no campo da antropologia social britânica. A sua sacada foi ver como as próprias sociedades sacaneiam-se a si mesmas, brincando com o perigo, e suscitando efeitos de paralisia em relação ao fluxo da vida cotidiana. Às margens, no límen, se produzem efeitos de estranhamento. Desloca-se o lugar olhado das coisas. Gera-se conhecimento. $O$ antropólogo procura acompanhar os movimentos surpreendentes da vida social. Turner se interessa por momentos de suspensão de papéis, ou interrupção do teatro da vida cotidiana. Em instantes como esses - de communitas - as pessoas podem ver-se frente a frente como membros de um mesmo tecido social. Daí, a importância dos dramas sociais, e dos rituais que os suscitam (através de rupturas socialmente instituídas) ou deles emergem (como expressões de uma ação reparadora). No espelho mágico dos rituais, onde elementos do cotidiano se reconfiguram, recriam-se universos sociais e simbólicos. ${ }^{4}$

\section{SEGUNDO MOMENTO: DO RITUAL AO TEATRO}

A seguir, o segundo momento de nosso rito de passagem. Aqui nos deparamos com um conjunto de textos exploratórios, pouco traduzidos, onde se encontram esboços de uma antropologia da performance e da 
experiência. São esses possivelmente os escritos menos conhecidos de Turner. Duas possíveis leituras desse momento na obra do autor se sugerem, ambas características de um rito de transição. Por um lado, a diminuição de vitalidade do pesquisador (a experiência de tomb): o distanciamento em relação ao trabalho etnográfico. Por outro, um renascimento (womb): Turner se permite correr novos riscos. Questiona-se. Interesses que se alojam em substratos de sua experiência afloram. Ganham força. Daí, a passagem do ritual ao teatro. E o encontro de Turner com Richard Schechner. Há indícios dessa inflexão na antropologia de Turner no prefácio de Dramas, Fields and Metaphors (Dramas, Campos e Metáforas), publicado em 1974, onde se discute a noção do "liminóide". Mas, os seus desdobramentos mais expressivos, onde se configuram a antropologia da performance e da experiência, aparecem nos anos de 1980, com a publicação de From Ritual do Theatre: the human seriousness of play (Do Ritual ao Teatro: a seriedade humana da brincadeira), em 1982, e de dois textos póstumos: The Anthropology of Performance (A Antropologia da Performance), em 1987, e “Dewey, Dilthey and Drama: an essay in the anthropology of experience" ("Dewey, Dilthey e Drama: um ensaio em antropologia da experiência"), em 1986. Evidencia-se nesses trabalhos uma premissa de fundo: a antropologia da performance é uma parte essencial da antropologia da experiência (Turner 1982:13). Através do processo de performance, o contido ou suprimido revela-se - Wilhelm Dilthey usa o termo Ausdruck, de ausdrucken, "espremer". Citando Dilthey, Turner descreve cinco "momentos" que constituem a estrutura processual de cada Erlebnis, ou experiência vivida: 1) algo acontece ao nível da percepção (sendo que a dor ou o prazer podem ser sentidos de forma mais intensa do que comportamentos repetitivos ou de rotina); 2) imagens de experiências do passado são evocadas e delineadas - de forma aguda; 3) emoções associadas aos eventos do passado são revividas; 4) o passado articula-se ao presente numa "relação musical" (conforme a analogia de Dilthey), tornando possível a descoberta e construção de significado; e 5) a experiência se completa através de uma forma de "expressão". Performance - termo que deriva do francês antigo parfournir, "completar" ou "realizar inteiramente" - refere-se, justamente, ao momento da expressão. A performance completa uma experiência (Turner 1982:13-14).

A figura de Dilthey aqui lampeja como uma espécie de espírito ancestral. Tal como num rito de cura, Turner nela encontra formas de lidar com a crise de nossa época: a dificuldade de significar o mundo. A seguir, alguns comentários pontuais a respeito das três publicações acima citadas.

From Ritual do Theatre: the human seriousness of play (1982). No primeiro capítulo, intitulado "Liminal to liminoid, in play, flow, ritual: an essay in comparative symbology" ("Liminar ao liminóide, em brincadeira, fluxo, ritual: um ensaio em simbologia comparada"), delineiam-se as idéias de Turner a respeito do impacto da Revolução Industrial sobre os gêneros de ação simbólica. Sociedades industrializadas produzem em relação aos processos de significar o mundo uma espécie de revolução copernicana. Provoca-se o descentramento e a fragmentação da atividade de recriação de universos simbólicos. Esferas do trabalho ganham autonomia. Como instância complementar ao trabalho, surge a esfera do lazer - que não deixa de se constituir como um setor do mercado. Processos liminares de produção simbólica perdem poder na medida em que, simultaneamente, geram 
e cedem espaço a múltiplos gêneros de entretenimento. As formas de expressão simbólica se dispersam, num movimento de diáspora, acompanhando a fragmentação das relações sociais. Trata-se de um sparagmos, ou desmembramento. $O$ espelho mágico dos rituais se parte. Em lugar de um espelhão mágico, poderíamos dizer, surge uma multiplicidade de fragmentos e estilhaços de espelhos, com efeitos caleidoscópicos, produzindo uma imensa variedade de cambiantes, irrequietas e luminosas imagens.

Nos substratos das novas formas de ação simbólica Turner descobre fontes do poder liminar. Em relação às formas liminares, as liminóides evidenciam duas características: 1) elas ocorrem às margens dos processos centrais de produção social (nesse sentido elas são menos "sérias"); e 2) elas podem ser mais criativas (e, até mesmo, subversivas).

"Dewey, Dilthey and Drama: an essay in the anthropology of experience" (1986). Intriga-me ver como a metanarrativa desse ensaio de Turner ilumina uma forma dramática. O período histórico que se inicia com a revolução industrial aparece, nos substratos do texto, como drama social. Algumas das idéias encontradas em From Ritual to Theatre retornam. A Revolução Industrial sinaliza um momento de "ruptura". A dificuldade liminóide de significar o mundo evidencia a "crise e intensificação da crise". Uma "ação reparadora" se enuncia no próprio título do texto: "Dewey" e "Dilthey" - autores que iluminam a categoria da experiência - e "drama social", conceito elaborado por Turner nos anos de 1950, e que aqui serve para evocar as fontes de poder liminar. Nesse contexto, onde se discute a categoria de experiência vivida (Erlebnis) de Dewey e Dilthey, essa ênfase no drama social chama atenção. Haveria em Turner a nostalgia por uma experiência que se expressa melhor na noção de Erfahrung do que na de Erlebnis? Ou seja, haveria nesse autor uma nostalgia por uma experiência coletiva, vivida em comum, passada de geração em geração, e capaz de recriar um universo social e simbólico pleno de significado? O "desfecho" do artigo vem ao estilo do "velho" (jovem) Turner: o teatro e outros gêneros liminóides de performance podem suscitar experiências de communitas. $\mathrm{O}$ autor escreve: “Um senso de harmonia com o universo se evidencia e o planeta inteiro é sentido como uma communitas" (Turner 1986:43).

Mas, talvez o que chame mais atenção seja um ruído que ocorre pouco antes desse desfecho. Turner comenta que o ritual e as artes performativas derivam do cerne ("coração") liminar do drama social - até mesmo, como acontece freqüentemente em "culturas declinantes", onde "o significado é de que não há significado" (Ibid: 43). No âmbito de uma experiência capaz de recriar universos sociais plenos de significado, lampeja uma visão de terra arrasada. As culturas do período posterior à Revolução Industrial se apresentam como "declinantes". 0 significado anula-se a si mesmo, sinalizando a sua própria ausência. A contrapelo de um desfecho otimista, e do entusiasmo do autor, se produz um ruído com efeitos de interrupção no fluxo da narrativa. Não seria esse ruído uma expressão da cautela de Turner em relação às experiências de communitas em "culturas declinantes"?

The Anthropology of Performance (1987). Em um capítulo que leva o mesmo título da coletânea, Turner evoca uma distinção feita por Chomsky entre "competência" e "performance" (Turner 1987a:76). "Competência", nesse contexto, se refere ao domínio sobre as regras subjacentes a uma língua: a sua gramática. A citação - que aqui surge 
possivelmente como uma des-leitura (criativa) em meio a uma polêmica com o estruturalismo - serve para ressaltar uma característica que Turner associa aos estudos de performance: a atenção aos elementos estruturalmente arredios. Tais estudos se interessam por agramaticalidades, atos falhos, elipses, hesitações, incoerências, erros e ruídos. Uma questão se coloca: o que dizer do ruído do próprio Turner que encontramos em “Dewey, Dilthey and Drama..."?

\section{TERCEIRO MOMENTO: ÀS MARGENS DAS MARGENS (COM BENJAMIN)}

Chegamos ao terceiro momento de nosso rito de passagem. Seria o momento do rito de reagregação, ou retorno a um lugar (estranhamente) familiar. Nos escritos de Turner esse movimento parece se sugerir através de um retorno constante da noção de drama social nas discussões. Aqui, porém, para fins de dizer algo sobre o ruído de Turner tomamos outro rumo. Isso, tendo em mente uma característica do mesmo autor: a sua atenção, como vimos, aos elementos estruturalmente arredios. E o olhar que vem das margens. Vamos, então, às margens das margens.

Ao se fazer esse deslocamento, talvez nos vejamos em companhia estranha (ou, de novo, estranhamente familiar). Chama atenção, nesse límen do límen, um conjunto de afinidades entre a antropologia de Victor Turner e o pensamento de Walter Benjamin. ${ }^{5}$ Menciono três. 1) Ambos os autores fazem uma espécie de arqueologia da experiência. Ao explorar os substratos de culturas contemporâneas, Turner encontra a experiência liminar. Benjamin se depara com a grande tradição narrativa, onde se forma uma experiência coletiva - Erfahrung ("do radical fahr - usado ainda no antigo alemão no seu sentido literal de percorrer, de atravessar uma região durante uma viagem") (cf. Gagnebin 1994:66). 2) Turner discute o enfraquecimento da experiência liminar, ou, como se pode inferir, o estilhaçamento do "espelho mágico" do ritual. Benjamin discute o declínio da grande tradição narrativa e, no estilhaçamento da tradição, o empobrecimento da experiência. 3) Nos novos gêneros de ação simbólica Turner descobre fontes do poder liminar. Nas novas formas narrativas Benjamin encontra indícios da grande tradição narrativa: o seu não-acabamento essencial e abertura às múltiplas possibilidades. Uma experiência com o passado, de onde irrompem esperanças ainda não realizadas, abre-se a partir da atenção aos ruídos.

O pensamento benjaminiano emerge possivelmente como um bom guia para explorar os ruídos de Turner. Isso, pelo modo como nele se reforçam algumas das desconfianças do próprio Turner em relação aos desfechos harmonizantes, e às manifestações efusivas de communitas na experiência contemporânea. Tais desfechos, com seus efeitos de esquecimento, não correriam o risco de suprimir os ruídos?

Uma audição dos ruídos não deixa de sugerir alguns desdobramentos. Uma "descrição densa" possivelmente adquire as qualidades de uma descrição tensa. ${ }^{6}$ Nas histórias que balineses e outros narradores contam para si sobre eles mesmos, ouvem-se os ruídos de elementos suprimidos. Lampejam imagens de uma memória involuntária (Benjamin 1995:106). E, depara-se, talvez, com um dos "segredos do bricoleur: os restos e as sobras de estruturas simbólicas que lhe são mais preciosas permanecem às margens de sua obra, escondidos nas dobras da cultura, em testemunho do inacabamento de suas 'soluções', configurando um acervo de coisas boas para fazer pensar". ${ }^{7}$ 

PERFORMANCE

A partir dos ruídos de um campo emergente, alguns deslocamentos do lugar olhado (e ouvido) das coisas podem se sugerir. Isso, tendo-se em vista a intuição auditiva de Victor Turner: as esperanças de uma formação cultural podem se encontrar nos ruídos. Algumas questões se apresentam:

1. Um duplo deslocamento: às margens das margens. Considerando-se que a experiência de communitas tende a irromper às margens, o ruído produzido por Turner não seria proveniente de um duplo deslocamento, às margens das margens?

2. Um duplo efeito de estranhamento: em relação ao cotidiano e ao extraordinário também. Considerandose que a experiência de communitas surge de um efeito de estranhamento que se produz em relação ao cotidiano, o ruído poderia suscitar um efeito inverso ao mesmo tempo - o estranhamento em relação ao extraordinário?

3. Um extraordinário cotidiano e cotidiano extraordinário. A questão talvez seja essa: o cotidiano não poderia ser tão ou mais espantoso quanto o extraordinário? Nesse caso, talvez seja preciso articular as abordagens de Erving Goffman, que se interessa pelo teatro da vida cotidiana, e de Victor Turner, que procura captar os momentos de interrupção, ou meta-teatro, para se falar de um meta-teatro cotidiano. Walter Benjamin escreve: "A tradição dos oprimidos nos ensina que o 'estado de exceção' é a regra" (1985b:226).

Aqui também emerge uma pergunta de rodapé (virando texto): seriam determinadas manifestações liminóides - com destaque aos ruídos que ocorrem às "margens das margens" dos processos centrais - mais fiéis, "em sua dimensão mais profunda", ao legado da experiência liminar do que certas tentativas de reviver uma experiência de communitas em meio ao esfacelamento das relações? ${ }^{8}$

\section{PARFOURNIR?}

De acordo com Victor Turner, como vimos, a experiência se completa através de uma forma de "expressão". Performance - termo que deriva do francês antigo parfournir, "completar" ou "realizar inteiramente" - refere-se, justamente, ao momento da expressão. A performance completa uma experiência. Porém, o que se entende por completar? Essencial à performance - e, aqui, também recorremos a Turner - é a sua abertura. Ou, em outros termos, o seu não-acabamento essencial. Daí, a sua atenção aos ruídos.

John Cowart Dawsey é professor associado (livre-docente) do Departamento de Antropologia da Universidade de São Paulo e coordenador do Núcleo de Antropologia da Performance e do Drama (Napedra) na mesma instituição. 
1 Uma versão deste artigo foi apresentada na mesa-redonda "Do Ritual à Performance: Abordagens teóricas num campo emergente no Brasil", coordenada por Esther Jean Langdon na 25a Reunião Brasileira de Antropologia (Goiânia, 13/06/2006). Mariza Peirano e Maria Laura Cavalcanti foram as outras participantes do evento. A ementa da mesa sublinhava que, "na reconfiguração do pensamento social contemporâneo, o campo da performance se apresenta como espaço interdisciplinar importante para a compreensão de gêneros de ação simbólica. A antropologia da performance, que surge nas interfaces de estudos do ritual e do teatro, amplia questões clássicas do ritual para tratar um conjunto de gêneros performativos encontrados em todas as sociedades do mundo globalizado, incluindo ritual, teatro, música, dança, festas, narrativas, cultos, manifestações étnicas, movimentos sociais, e encenações da vida cotidiana. No encontro com questões de performance e performatividade, os próprios estudos de ritual se renovam. O objetivo desta proposta de mesa-redonda é propiciar uma oportunidade para reflexão sobre diferentes abordagens e recortes conceituais no campo da antropologia da performance, com destaque às relações entre performance e ritual. Assim, propõe-se um diálogo entre pesquisadores que se inspiram nos trabalhos de Victor Turner, Richard Schechner, Stanley Tambiah, e Richard Bauman, entre outros, para fins de explorar possíveis desdobramentos analíticos do campo, e situar um universo de problemas pertinentes na literatura". Algumas das formulações deste trabalho se inspiram em texto publicado na Cadernos de Campo (Dawsey 2005a).

2 N.E.: Ver nota 1 acima.

3 "Túmulo e útero", um jogo de palavras recorrente nos textos de Turner.

4 Trata-se de uma metáfora recorrente nos escritos de Turner. Ver, por exemplo, Turner 1987b:22. Em outro texto escrevi: “Experiências de liminaridade podem suscitar efeitos de estranhamento em relação ao cotidiano. Enquanto expressões de experiências desse tipo, performances rituais e estéticas provocam mais do que um simples espelhamento do real. Instaura-se, nesses momentos, um modo subjuntivo ('como se') de situar-se em relação ao mundo, provocando fissuras, iluminando as dimensões de ficção do real - $f(r)$ iccionando-o, poder-se-ia dizer - revelando a sua inacababilidade e subvertendo os efeitos de realidade de um mundo visto no modo indicativo, não como paisagem movente, carregada de possibilidades, mas simplesmente como é. Performance não produz um mero espelhamento. A subjuntividade, que caracteriza um estado performático, surge como efeito de um 'espelho mágico'" (Dawsey 2006: 136).

5 As aberturas para uma antropologia benjaminiana tornam-se expressivas nos estudos de Michael Taussig. Cf. Taussig (1980, 1986, 1993).

6 A idéia de uma descrição tensa é desenvolvida a partir do conceito de Walter Benjamin de imagem dialética. O ato etnográfico poderia então ser definido como a busca por uma "'descrição tensa', carregada de tensões, capaz de produzir nos próprios leitores um fechar e abrir de olhos, uma espécie de assombro diante de um cotidiano agora estranhado, um despertar" (Cf. Dawsey 1999:64).

7 A elaboração inicial dessa idéia se encontra em Dawsey (2005b:31).

8 Estou parafraseando a frase de Jeanne Marie Gagnebin, que, numa análise do ensaio benjaminiano sobre "a obra de arte na era da reprodutibilidade técnica", escreve: "Essas tendências 'progressistas' da arte moderna, que reconstroem um universo incerto a partir de uma tradição esfacelada, são, em sua dimensão mais profunda, mais fiéis ao legado da grande tradição narrativa que as tentativas previamente condenadas de recriar o calor de uma experiência coletiva ('Erfahrung') a partir das experiências vividas isoladas ('Erlebnisse')". Ela completa: "Essa dimensão, que me parece fundamental na obra de Benjamin, é a da abertura". Cf. Gagnebin 1985:12; Benjamin 1985a:165-196. 


\section{REFERÊNCIAS BIBLIOGRÁFICAS}

BARTHES, Roland. 1990. “Diderot, Brecht, Eisenstein”. In R. Barthes O Óbvio e o Obtuso: Ensaios Críticos. Rio de Janeiro: Nova Fronteira.

BENJAMIN, Walter. 1985a. "A Obra de Arte na Era de Sua Reprodutibilidade Técnica". In W. Benjamin. Obras Escolhidas I: Magia e Técnica, Arte e Política. São Paulo: Brasiliense.

. 1985b. "Sobre o Conceito de História". In W. Benjamin. Obras Escolhidas I: Magia e Técnica, Arte e Política. São Paulo: Brasiliense.

. 1995. "Sobre Alguns Temas em Baudelaire". In W. Benjamin. Obras Escolhidas III: Charles Baudelaire. Um Lírico no Auge do Capitalismo. São Paulo: Brasiliense.

DAWSEY, John Cowart. 1999. De Que Riem os "Bóias-Frias"? Walter Benjamin e o Teatro Épico de Brecht em Carrocerias de Caminhões. Tese de livre-docência. São Paulo: PPGAS/FFLCH, Universidade de São Paulo.

. 2005a. "Victor Turner e Antropologia da Experiência". Cadernos de Campo 13:110-121.

2005b. “O Teatro dos 'Bóias-Frias': repensando a antropologia da performance". Revista Horizontes Antropológicos 11(24): $15-34$.

2006. “O Teatro em Aparecida: a santa e a lobisomem". Mana - Estudos de Antropologia Social 12(1): 135-150.

GAGNEBIN, Jeanne Marie. 1985. “Prefácio: Walter Benjamin ou a História Aberta”. In W. Benjamin. Obras Escolhidas I: Magia e Técnica, Arte e Política. São Paulo: Brasiliense.

. 1994. História e Narração em Walter Benjamin. São Paulo: Perspectiva.

GEERTZ, Clifford. 1978. “Uma Descrição Densa: Por uma teoria interpretativa da cultura”. In C. Geertz. A Interpretação das Culturas. Rio de Janeiro: Zahar.

TAUSSIG, Michael. 1980. The Devil and Commodity Fetishism in South America. Chapel Hill: University of North Carolina Press.

1986. Shamanism, Colonialism, and the Wild Man: a study in terror and healing. Chicago/London: The University of Chicago Press.

. 1993. Mimesis and Alterity. New York/London: Routledge.

TURNER, Victor. 1982. "Introduction". In V. Turner. From Ritual to Theatre: the human seriousness of play. New York: PAJ Publications.

. 1986. “Dewey, Dilthey, and Drama: an essay in the anthropology of experience". In V. Turner e E. M. Bruner (orgs.). $\overline{T h e}$ Anthropology of Experience. Urbana e Chicago: University of Illinois Press.

Publications.

. 1987a. "The Anthropology of Performance". In V. Turner. The Anthropology of Performance. New York: PAJ

. 1987b. "Images and Reflections: Ritual, Drama, Carnival, Film and Spectacle in Cultural Performance". In V. Turner. $\overline{T h e}$ Anthropology of Performance. New York: PAJ Publications. 


\section{Turner, Benjamin e Antropologia da Performance: o lugar olhado (e ouvido) das coisas}

\section{RESUMO}

Um exercício aqui se propõe: repensar o lugar olhado das coisas na antropologia da performance. Isso, a partir de uma audição dos ruídos. $O$ texto se desenvolve tal como um rito de passagem, em três momentos. Iniciamos com um rito de separação, saindo de um lugar (supostamente) familiar: os estudos de Victor Turner sobre ritos e dramas sociais. O movimento nos leva em direção a um lugar menos conhecido, onde nos deparamos, tal como num rito de transição, com os textos de Turner sobre a antropologia da performance e da experiência. Num terceiro momento, ao invés de fazermos um regresso, tal como num rito de reagregação, vamos às margens das margens. No límen da escritura de Turner, com as atenções voltadas aos ruídos, nos vemos em companhia (estranhamente familiar) de Walter Benjamin. Uma premissa se apresenta: os lugares onde um texto se desmancha podem ser os mais fecundos. PALAVRAS-CHAVE: antropologia da performance, antropologia da experiência, teatro, ritual, ruído.

\section{Turner, Benjamin and the Anthropology of Performance: the place from where things are seen (and heard)}

\section{ABSTRACT}

In the following exercise an attempt is made to rethink the place from which things are seen in the anthropology of performance. This involves ability for hearing noise. The paper unfolds as a sort of rite of passage. One begins with a separation rite, in a supposedly familiar place: Victor Turner's studies of rites and dramas. Then one journeys into possibly less familiar places, such as in a rite of transition, so as to discuss Turner's studies in the anthropology of experience and performance. Finally, instead of enacting a rite of incorporation, movement is made towards the margins, or, better, margins of margins. In liminal areas of Turner's writings, attuned to noises, we find ourselves in the (strangely familiar) company of Walter Benjamin. Perhaps some of the places where texts seem to be coming apart may be the most fertile. KEY WORDS: anthropology of performance, anthropology of experience, theater, ritual, noise. 